\title{
The Research of Connection between Degree of Polymerization and Frequency Domain Dielectric Spectroscopy Characteristics during Oil-Paper Insulation Aging
}

\author{
Danyu Jiang1,2, Guangning Wu1 ${ }^{1}$, Xian Yang², Qingkai Hao² \\ ${ }^{1}$ ASchool of Electrical Engineering College, Southwest Jiaotong University, Chengdu, China \\ ${ }^{2}$ Electric Power Research Institute of Guangdong Power Grid Corporation, Guangzhou, China \\ Email:yujay9@sina.com
}

How to cite this paper: Jiang, D.Y., Wu, G.N., Yang, X. and Hao, Q.K. (2017) The Research of Connection between Degree of Polymerization and Frequency Domain Dielectric Spectroscopy Characteristics during Oil-Paper Insulation Aging. Energy and Power Engineering, 9, 667-674.

https://doi.org/10.4236/epe.2017.94B072

Received: March 9, 2017

Accepted: March 30, 2017

Published: April 6, 2017

\begin{abstract}
In order to study the linkage effects between degree of polymerization and frequency domain dielectric spectroscopy characteristics of oil-paper insulation, the frequency domain dielectric response test platform of oil-paper insulation is set up. Complex permittivity of oil-paper insulation respectively composed by new or aged oil and insulation paper with different DP are tested, and complex permittivity of oil-paper insulation respectively composed by insulation respectively composed by new oil and insulation paper with different DP and low or high moisture content are tested. The test results are analyzed, and the analysis results show that the degree of polymerization of insulation paper has an influence on complex permittivity of oil-paper insulation though influencing the distribution of moisture and acids between oil and paper.
\end{abstract}

\section{Keywords}

Degree of Polymerization, Oil-Paper Insulation, Frequency

Domain Dielectric Spectroscopy, Moisture

\section{Introduction}

As the promotion of transmission voltage, oil-immersed power transformers in power systems become more and more important. Oil-paper insulation is an oil immersion major component of the internal insulation of power transformers in the transformer. The effect of thermal stress on the long-term operation of the device can lead oil-paper insulation to the decline of its insulation performance 
[1]. The faults caused by transformer insulation performance degradation accounts for about $80 \%$ of the total faults, and aging of oil paper insulation failures accounts for a large proportion. Therefore, accurate diagnosis of oil paper insulation aging degree has very important practical significance [2].

Frequency domain dielectric spectroscopy (FDS) is an non-destructive diagnostic method. When FDS was introduced to insulation fault diagnosis for power transformers, it was received wide attention of scholars. Compared with the chemical analysis, FDS is an accurate and reliable method to determine the moisture content of the paper insulation and insulation oil conductivity [3].

Oil-paper insulation aging process is easy to produce water and acid [4]. Heat insulating paper, electrical, mechanical, aging water and acid synergistic can decrease the degree of polymerization of transformer when operation time increases. The decline in the degree of insulation paper is not recoverable, and the insulation performance of the insulation paper can also be reduced [5]. So, this paper study the influence of DP on frequency domain dielectric spectroscopy characteristics of oil-paper insulation and the mechanisms, and frequency domain dielectric response test platform of oil- paper insulation is set up.

\section{FDS Principle and Experiment}

\subsection{FDS Principle}

Variable voltage $U(t)$ across the capacitor plates produce a uniform electric field $E(t)=U(t) / d$ between the plates, where $\mathrm{d}$ is the distance between two plates [6]. The electric potential of the electrodes $D(t)$ is composed of the instantaneous contribution of vacuum $\varepsilon_{0} E(t)$ and the polarization response of inertia delay $P(t)$,

$$
D(t)=\varepsilon_{0} E(t)+P(t)
$$

The full current density is known by Maxwell equation

$$
J=\sigma_{0} E+\partial D / \partial \mathrm{t}
$$

where $\sigma_{0}$ is DC conductivity, Fourier transform of (2)

$$
\begin{gathered}
J(\omega)=\sigma_{0} E(\omega)+j \omega D(\omega) \\
J(\omega)=j \omega \varepsilon_{0}\left\{\varepsilon_{\infty}+\chi^{\prime}(\omega)-j\left[\frac{\sigma_{0}}{\varepsilon_{0} \omega}+\chi^{\prime \prime}(\omega)\right]\right\} E(\omega) \\
=j \omega \varepsilon_{0}\left[\varepsilon^{\prime}(\omega)-\varepsilon^{\prime \prime}(\omega)\right] E(\omega)
\end{gathered}
$$

where $\chi^{\prime \prime}(\omega)$ and $\chi^{\prime}(\omega)$ are the real and imaginary parts of repolarization coefficient, $\varepsilon^{\prime}(\omega)$ and $\varepsilon^{\prime \prime}(\omega)$ are the real and imaginary parts of the complex permittivity .

\subsection{FDS Experiment}

The template is used to format your paper and style the text. All margins, column widths, line spaces, and text fonts are prescribed; please do not alter them. You may note peculiarities. For example, the head margin in this template measures proportionately more than is customary. This measurement and others 
are deliberate, using specifications that anticipate your paper as one part of the entire journals, and not as an independent document. Please do not revise any of the current designations.

Experimental materials used in this paper are transformer insulation paper and mineral insulating oil, details of materials shown in Table 1.

According to Table 1, different degree of polymerization of insulation paper can be obtained. Measuring the degree of polymerization of insulating paper is reference for GB 1548-2004. In order to reduce the measurement error, three samples are measured, and the average value of the degree of polymerization of three samples is used as the degree of polymerization. (Table 2) Because small molecule acid has a great impact on frequency domain dielectric response characteristics of oil paper insulation [7], so this paper use the small molecule acid-_Formic acid. Test principle diagram and test apparatus are shown in Figure 1.

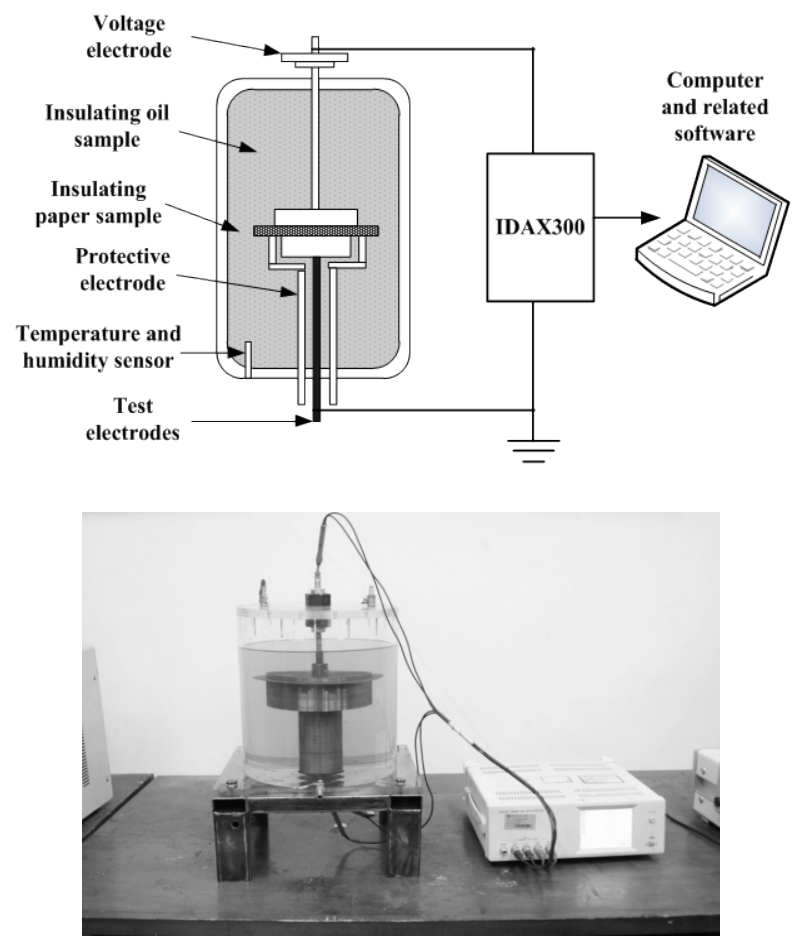

Figure 1. Experimental schematic and setup.

Table 1. The material information.

\begin{tabular}{cccc}
\hline Material & Material Type & Moisture content (\%) & Degree of polymerization \\
\hline Insulating paper & $0.3 \mathrm{~mm}$ Thick kraft paper & 6.5 & 1131 \\
Insulating oil & 25\# naphthenic oil & $17.9 \times 10^{-4}$ & - \\
\hline
\end{tabular}

Table 2. Pre-conditional process of paper with different DP.

\begin{tabular}{cc}
\hline DP & Pre-conditional process \\
\hline 1131 & $100^{\circ} \mathrm{C} / 50 \mathrm{~Pa} / 2 \mathrm{~d}$ \\
775 & $100^{\circ} \mathrm{C} / 50 \mathrm{~Pa} / 20 \mathrm{~d}$ \\
326 & $150^{\circ} \mathrm{C} / 50 \mathrm{~Pa} / 35 \mathrm{~d}$ \\
\hline
\end{tabular}




\section{Experimental Result Analysis}

\subsection{Analysis of Frequency Domain Dielectric Spectrum of New Insulation Oil and Insulation Paper}

Define abbreviations and acronyms the first time they are used in the text, even after they have been defined in the abstract. Abbreviations such as IEEE, SI, MKS, CGS, sc, dc, and rms do not have to be defined. Do not use abbreviations in the title or heads unless they are unavoidable.

Figure 2 shows complex permittivity measurement curve. The degree of polymerization are 1131, 775, 326 of insulating paper which is composed of new insulation oil. Compared with different polymerization degree of insulation, the influence on complex permittivity of the real and imaginary parts is very small.

\subsection{Analysis of Frequency Domain Dielectric Spectrum of Small Molecule Acid-Containing Oil Paper Insulation and DP}

Put different degree of polymerization of the insulating paper in a high initial small molecule acid content (acid value $0.3 \mathrm{mg} \mathrm{KOH} / \mathrm{g}$ ) insulation oil, the balance distribution of the small molecule acid is shown in Table 3.

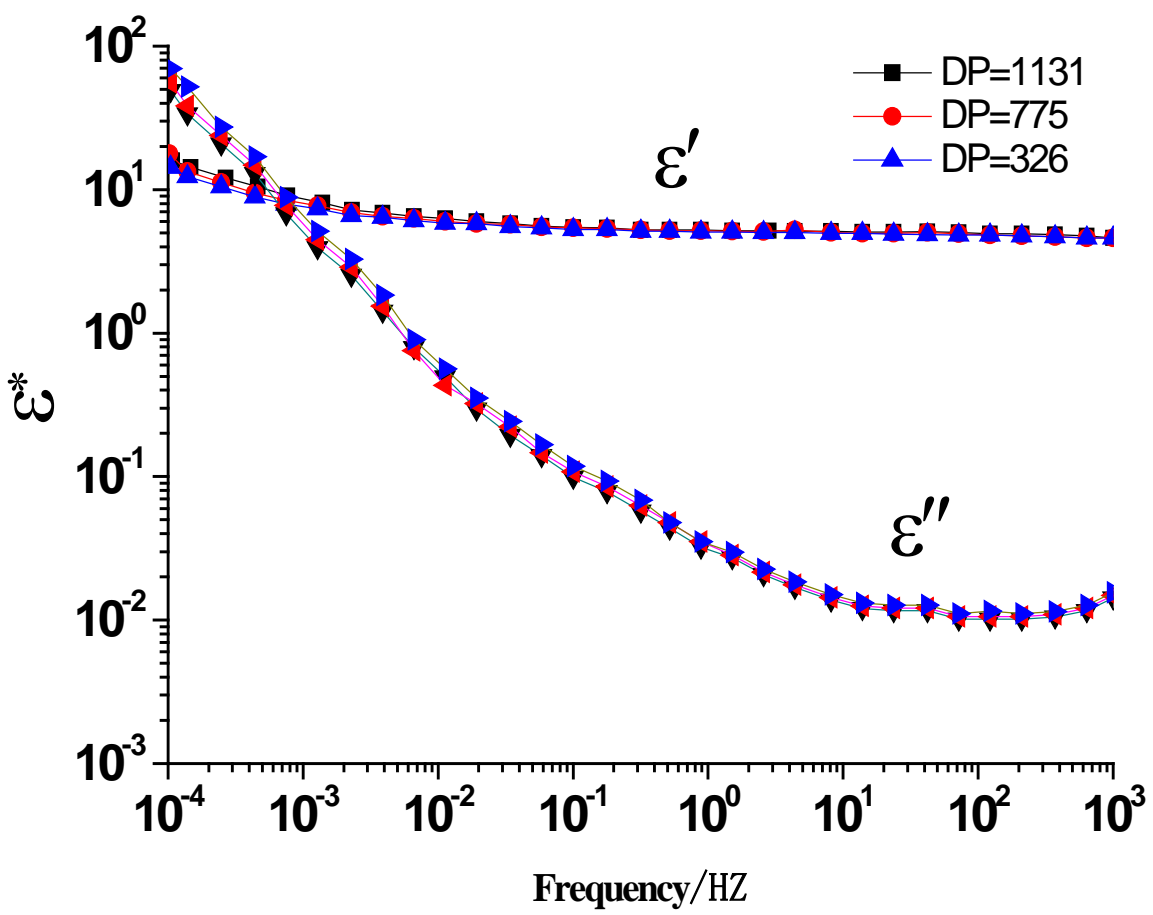

Figure 2. Complex permittivity ofnew oil-paperwith different DP.

Table 3. Distribution of acid between oil and paper with different DP.

\begin{tabular}{cccc}
\hline DP & Acid in oil (mg KOH/g) & Acid in oil (mgKOH/g) & Ratio of paper and oleic acid value \\
\hline 1131 & 0.063 & 4.74 & 75.2 \\
775 & 0.041 & 5.18 & 126.3 \\
326 & 0.048 & 5.04 & 105 \\
\hline
\end{tabular}


Figure 3 shows the complex permittivity testing curves of different polymerization degree of insulation paper with high initial small molecule acid content ( $0.3 \mathrm{mg} \mathrm{KOH} / \mathrm{g}$ ) insulation oil composition of oil paper insulation. Compared with the real and imaginary parts of the complex permittivity, when the insulating oil initial small molecule acid content is relatively high, the decrease of DP of insulating paper make different influence on complex permittivity of the real and imaginary parts. It is mainly reflected in the low frequency region. With the decrease of the degree of insulation paper, the amplitude of the complex permittivity and imaginary part of the dielectric constant increase, and the rate of the curve decrease.

\subsection{Analysis of Frequency Domain Dielectric Spectrum of Insulation Paper with Aging Insulation Oil}

Figure 4 shows the colour of new oil, 15 days- aged oil and 20 days-aged oil in experiment. The rightmost oil sample has been aged for 20 days whose moisture is $150 \mathrm{ppm}$ and acid content is $0.12 \mathrm{mg} \mathrm{KOH} / \mathrm{g}$. Table 4 shows the moisture and acid equilibrium distribution between 20 days aged oil and paper with different DP whose initial moisture content is $2 \%$.

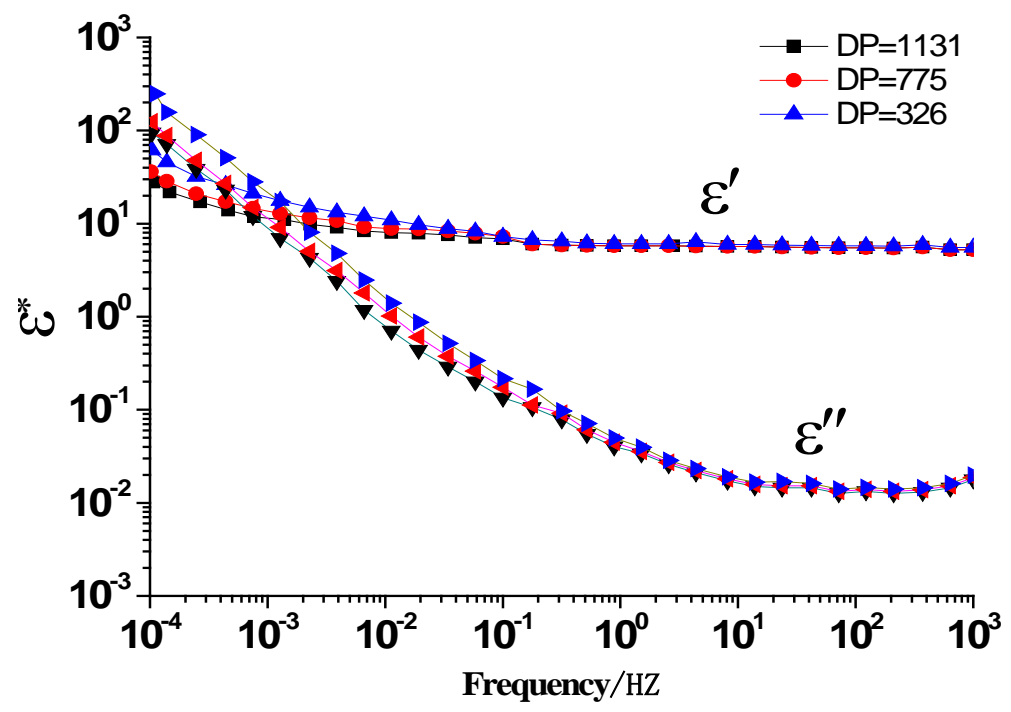

Figure 3. Complex permittivity of oil with high initial light acid content-paper with different DP.

Table 4. Distribution of moisture and acids between oil and paper in group of aged oil and insulation paper with different DP.

\begin{tabular}{ccccc}
\hline & \multicolumn{2}{c}{ Insulating oil } & \multicolumn{2}{c}{ Insulating paper } \\
\cline { 2 - 5 } DP & Water content/ppm & $\begin{array}{c}\text { Acid value } \\
(\mathrm{mgKOH} / \mathrm{g})\end{array}$ & Water content/ppm & $\begin{array}{c}\text { Acid value } \\
(\mathrm{mgKOH} / \mathrm{g})\end{array}$ \\
\hline 1131 & 42 & 0.0957 & 22160 & 0.486 \\
775 & 54 & 0.0926 & 21920 & 0.548 \\
326 & 81 & 0.0931 & 21380 & 0.558 \\
\hline
\end{tabular}




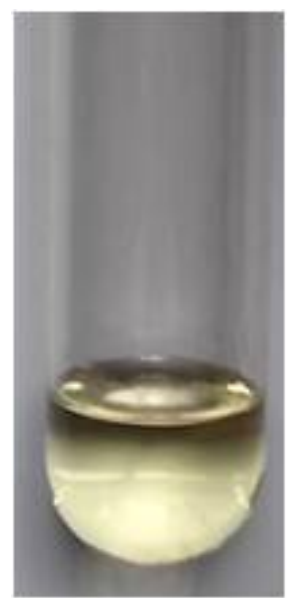

New oil

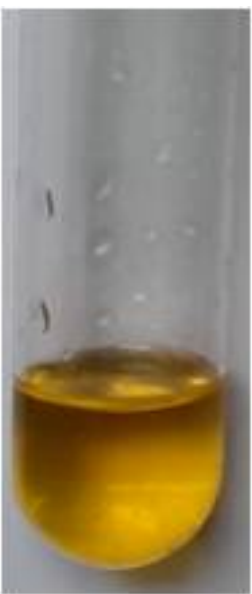

Aged $15 \mathrm{~d}$

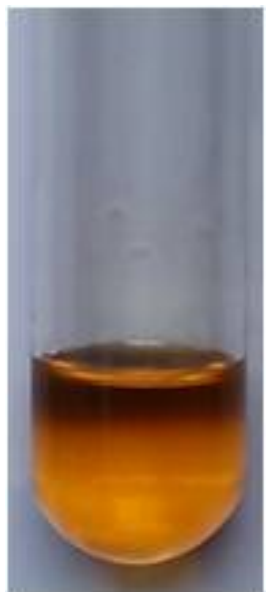

Aged $20 \mathrm{~d}$

Figure 4. Color contrast figure of aged and new oil.

Figure 5 shows the complex permittivity of oil-paper with different DP from experiment. With the decrease of DP, the real and imaginary part of complex permittivity tend to increase in the whole texting frequency range, and the increasing width is larger in low frequency range which make the real and imaginary part decrease more precipitously in low frequency along with the increase of frequency. The acid contained in the aged insulating oil is mainly macromolecular acid, and it would not draw manifest effect on FDS property of oil-paper system. Due to the aging of insulating oils and different polymerization degree of insulation paper initial contain a certain amount of moisture, when different degree of polymerization of insulating paper cause the same initial moisture content, it influence oil paper insulation frequency domain dielectric spectrum characteristics. The impact test results similar to Figure 3, which shows that interpretation is reasonable.

\section{Conclusions}

1) When insulating oil of small molecule acid content is high, the decreases of DP of insulating paper have a great impact on paper insulation complex permittivity, and the impact of the low frequency region is mainly reflected in the test.

2) For light acids, the decreasing of DP has an influence on Complex permittivity of oil-paper insulation only when oil-paper insulation has high light acid content, and the influence is mainly manifested in the low frequency area of the test. For moisture, the decreasing of DP has already affected Complex permittivity of oil-paper insulation largely when oil-paper insulation has low moisture content, and the impact is mainly manifested in the low frequency area of the test. While the moisture content is higher, the impact is manifested clearly in all frequency area of the test.

3) The degree of polymerization of insulation paper has an influence on complex permittivity of oil-paper insulation though influencing the distribution of moisture and acids between oil and paper. 


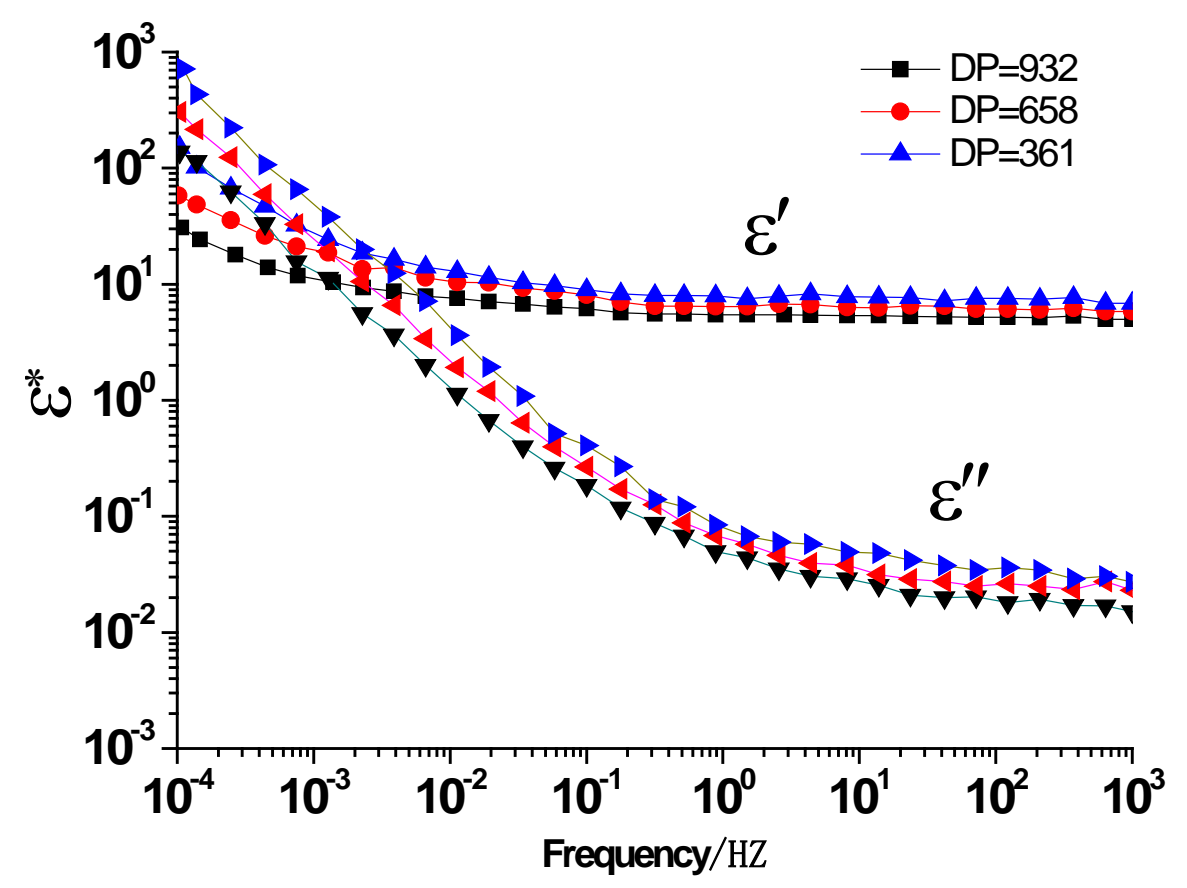

Figure 5. Complex permittivity of aged oil-paperwith different DP.

4) When the frequency domain dielectric spectroscopy is used to diagnose the moisture or acids content in oil-paper insulation, it should be considered that the effect of DP on the distribution of moisture and acids between oil and insulation paper has an impact on the frequency domain dielectric spectroscopy characteristics of oil-paper insulation.

\section{Acknowledgements}

The authors would like to thank National Natural Science Foundation of China for supporting this project.

\section{References}

[1] Gobi, K., Supramaniam, Hussien, Z. F., Aizam, M. (2008) Application of Frequency Domain Spectroscopy (FDS) in Assessing Dryness And Ageing State of Transformer Insulation Systems. IEEE International Conference on Power and Energy, 55-56, 2008.

[2] Gielniak, C., Ekanaykake, K., Walczak (2005) Dielectric Responses of New and Aged Transformer Pressboard in Dry and Wet States. International Symposium on Electrical Insulating Materials, 386-389.

[3] Boss, P., Csepes, G. and Der, H.V. (2003) Dielectric Response Methods for Diagnostics of Power Transformers. IEEE Electrical Insulation Magazine, 19, 12-18. https://doi.org/10.1109/MEI.2003.1203017

[4] Lundgaard, L. E., Hansen, W. and Ingebrigtsen, S. (2008) Ageing of Mineral Oil Impregnated Cellulose by Acid Catalysis. IEEE Transactions on Dielectrics and Electrical Insulation, 15,540-560. https://doi.org/10.1109/TDEI.2008.4483475

[5] Du, Y., Zahn, M. and Lesieutre, B. C. (1999) Moisture Equilibrium in Transformer Paper-Oil Systems. (1999)IEEE Electrical Insulation Magazine, 15, 11- 12. 
https://doi.org/10.1109/57.744585

[6] Linhjell, D. and Lundgaard, L. (2007) Dielectric Response of Mineral Oil Impregnated Cellulose and the Impact of Aging. (2007)IEEE Transaction on Dielectrics and Electrical Insulation, 14,156-169. https://doi.org/10.1109/TDEI.2007.302884

[7] Wang, W., Ma, Z.Q. and Li, C.G. (2012) Impact of Cellulose Aging on Moisture Equilibrium of Oil-Pressboard Insulation. Proceedings of the CSEE, 32,100-105.(in Chinese)

Submit or recommend next manuscript to SCIRP and we will provide best service for you:

Accepting pre-submission inquiries through Email, Facebook, LinkedIn, Twitter, etc. A wide selection of journals (inclusive of 9 subjects, more than 200 journals)

Providing 24-hour high-quality service

User-friendly online submission system

Fair and swift peer-review system

Efficient typesetting and proofreading procedure

Display of the result of downloads and visits, as well as the number of cited articles Maximum dissemination of your research work

Submit your manuscript at: http://papersubmission.scirp.org/

Or contact epe@scirp.org 